he did for electricity what Newton had done with gravity: related the heavens to the Earth. It was as an electrician that Franklin was lured into the practice of medicine: he was several times asked to electrify patients with nervous disorders. Always suspicious of grand speculation, and a careful observer, he never claimed more for the therapeutic potential of his brainchild than his own experience warranted.

Several of his interactions with medicine have biographical poignancy. He advocated inoculation for smallpox (he died shortly before Edward Jenner introduced vaccination), but lost one of his own uninoculated children to the disease. Ever alert to the dangers of lead poisoning (among printers who used lead type, as well as other occupational groups), Franklin collaborated with George Baker, the British physician who exposed its high levels in cider and other alcoholic drinks kept in lead vats. Franklin himself loved Madeira and port, two likely sources of toxic levels of the metal. He suffered from gout and bladder stones, a probable consequence of the poison to which he helped alert the public.

There were other inconsistencies in his philosophy of health. He advocated the healthgiving properties of fresh air, although as a social man he thrived in the clubs of urban centres such as Philadelphia, London and Paris. He also preached the virtues of exercise, believing that swimming was an undervalued activity, and swam even after he became very corpulent in his old age.

Other medical contributions were unambiguous. Franklin invented and wore bifocals, and used an ingenious mechanical arm to grasp books and other objects on high shelves, a natural consequence of his large private library. He was a founder of the first public hospital in America, the Pennsylvania Hospital. So close was his relation to medicine that the French occasionally assumed that he was medically qualified; in fact, 'Doctor Franklin' had several honorary degrees but no formal medical training. Nor did he apparently need it. He moved easily in medical and scientific circles, respected by the French and welcomed in Britain even after the United States had severed its ties with the mother country. Franklin had signed the Declaration of Independence, but he was always a man of peace. As he wrote in 1783: "There never was a good war, or a bad peace."

W. F. Bynum is at the Wellcome Trust Centre for the History of Medicine, University College London, London NW12BE, UK.

\section{MORE ON BENJAMIN FRANKLIN The First Scientific American: Benjamin Franklin and the Pursuit of Genius by Joyce E. Chaplin \\ Basic Books: 2006. 362 pp. $\$ 27.50$}

\title{
Home from home
}

\section{History is brought to life at Benjamin Franklin's house in London.}

\begin{abstract}
Colin Martin
Arguably the most famous American in the Age of the Enlightenment, Benjamin Franklin achieved scientific fame by flying a silk kite with a wire rod at one end and a key at the other into a thunderstorm in Philadelphia in 1752. He thus demonstrated that lightning consists of flashes of electricity.

During his long life, Franklin
\end{abstract} made many contributions to several branches of science. He found research a welcome respite from his role negotiating the turbulent complexities of contemporary diplomacy, including the repeal of stamp duty, which the British parliament had imposed on its American colonies in 1765 .

This year marks the 300th anniversary of Franklin's birth, the cue for activities around the world (see www.benfranklin300.org). It has been celebrated in London by the public opening of the 1730s Georgian townhouse, at 36 Craven Street, where he lived for 16 years as an agent for the Pennsylvania Assembly. The newly restored house serves as a museum and education centre (see www.benjaminfranklinhouse.org).

During his years in London, Franklin invented bifocal spectacles; developed a fuel-efficient fireplace draught called the Franklin stove; installed a new, more effective lightning rod on the dome of St Paul's Cathedral; and invented the glass armonica (or harmonica), with its haunting

sound described as "the voice of angels".

He worked with Joseph Priestley on experiments that led to the discovery of oxygen; recorded the effects of the Gulf Stream and other ocean currents; investigated canal depths and their implication for transport; and demonstrated the veracity of the old adage that oil calms

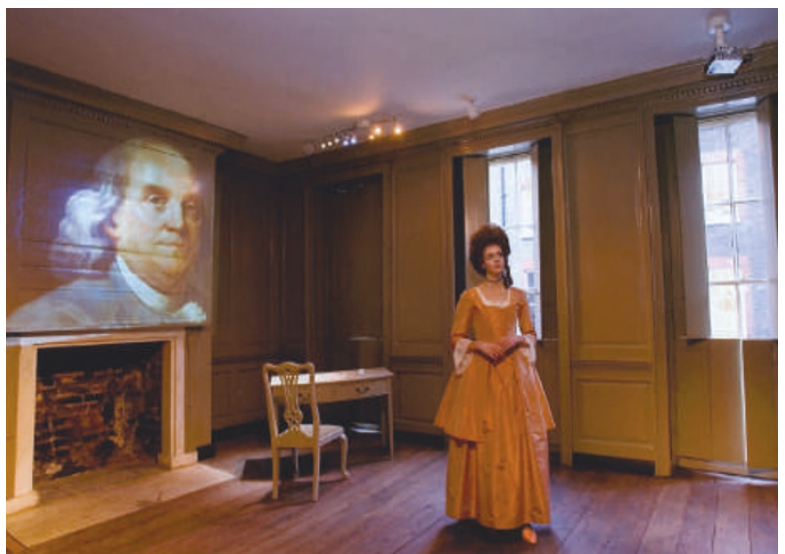

Tour de force? Polly acts as guide in Franklin's London home.

account of coagulation. Hewson lived at the house from 1770 to 1774 after he married Polly Stevenson, the daughter of Franklin's landlady. The medical-history room in the science study centre continues this tradition with ingenious models and touch-screen computers to encourage schoolchildren to think about how the human body works.

The house is interpreted for visitors in an evocative 'museum as theatre' tour, which incorporates state-of-the art audiovisual display techniques and an actress in eighteenth-century dress who plays the role of Polly (see picture). Polly's interest in Franklin's diplomacy and science made her one of his closest confidantes. "After writing six folio pages of scientific philosophy to a young girl, is it necessary to finish such a letter with a compliment?" asks Franklin during an audiovisual presentation. "Is not such a letter of itself a compliment?"

Despite his skilled diplomacy,

troubled water, on a windswept pond in the London suburb of Clapham. Some of these achievements are recreated as hands-on experiments for school children at the centre as an introduction to scientific methodology.

During the recent restoration of the house, some 1,200 human bones were found in the basement. They were identified as remains from an anatomy school founded at the house by William Hewson, a British anatomist who identified the role of fibrinogen in 1770 and gave the first valid and his satirical Rules By Which a Great Empire May be Reduced to a Small One, written in 1773 to warn the intransigent British of the dangers of taking a hard line against hot-headed American colonists, Franklin failed to avert the War of Independence. In 1775, he hurriedly left Craven Street. By the time he had returned to Philadelphia, the American Revolution had begun. He died in 1790 at Passy near Paris, with Polly and Franklin's own daughter Sally at his bedside. Colin Martin is a writer based in London. 